\title{
Trade-off between morphological convergence and opportunistic diet behavior in fish hybrid zone Emmanuel Corse ${ }^{\dagger 1}$, Caroline Costedoat* ${ }^{*}{ }^{1}$, Nicolas Pech ${ }^{1}$, Rémi Chappaz ${ }^{1}$, Jonathan Grey ${ }^{2}$ and André Gilles ${ }^{1}$
}

Address: ${ }^{1}$ Aix-Marseille Université, CNRS, UMR 6116 - IMEP, Equipe Evolution Génome Environnement, Centre Saint Charles, case 36,3 place Victor Hugo, 13331 Marseille, France and ${ }^{2}$ School of Biological and Chemical Sciences, Queen Mary, University of London, Mile End Road, London E1 4NS, UK

Email: Emmanuel Corse - emmanuel.corse@univ-provence.fr; Caroline Costedoat* - caroline.costedoat@univ-provence.fr; Nicolas Pech - nicolas.pech@univ-provence.fr; Rémi Chappaz - remi.chappaz@univ-provence.fr; Jonathan Grey - j.grey@qmul.ac.uk; André Gilles - andre.gilles@univ-provence.fr

* Corresponding author †Equal contributors

Published: 27 October 2009

Frontiers in Zoology 2009, 6:26 doi:10.1186/1742-9994-6-26
Received: 13 April 2009

Accepted: 27 October 2009

This article is available from: http://www.frontiersinzoology.com/content/6/1/26

(C) 2009 Corse et al; licensee BioMed Central Ltd.

This is an Open Access article distributed under the terms of the Creative Commons Attribution License (http://creativecommons.org/licenses/by/2.0), which permits unrestricted use, distribution, and reproduction in any medium, provided the original work is properly cited.

\begin{abstract}
Background: The invasive Chondrostoma nasus nasus has colonized part of the distribution area of the protected endemic species Chondrostoma toxostoma toxostoma. This hybrid zone is a complex system where multiple effects such as inter-species competition, bi-directional introgression, strong environmental pressure and so on are combined. Why do sympatric Chondrostoma fish present a unidirectional change in body shape? Is this the result of inter-species interactions and/or a response to environmental effects or the result of trade-offs? Studies focusing on the understanding of a trade-off between multiple parameters are still rare. Although this has previously been done for Cichlid species flock and for Darwin finches, where mouth or beak morphology were coupled to diet and genetic identification, no similar studies have been done for a fish hybrid zone in a river. We tested the correlation between morphology (body and mouth morphology), diet (stable carbon and nitrogen isotopes) and genomic combinations in different allopatric and sympatric populations for a global data set of I 330 specimens. To separate the species interaction effect from the environmental effect in sympatry, we distinguished two data sets: the first one was obtained from a highly regulated part of the river and the second was obtained from specimens coming from the less regulated part.

Results: The distribution of the hybrid combinations was different in the two part of the sympatric zone, whereas all the specimens presented similar overall changes in body shape and in mouth morphology. Sympatric specimens were also characterized by a larger diet behavior variance than reference populations, characteristic of an opportunistic diet. No correlation was established between the body shape (or mouth deformation) and the stable isotope signature.

Conclusion: The Durance River is an untamed Mediterranean river despite the presence of numerous dams that split the river from upstream to downstream. The sympatric effect on morphology and the large diet behavior range can be explained by a tendency toward an opportunistic behavior of the sympatric specimens. Indeed, the similar response of the two species and their hybrids implied an adaptation that could be defined as an alternative trade-off that underline the importance of epigenetics mechanisms for potential success in a novel environment.
\end{abstract}




\section{Background}

Biologists have long recognized that introduced species may have major effects on native communities. If an invading species occupies the same niche as a native species, strong interactions are likely to occur [1]. Species are said to compete when they have negative effects on each other by consuming or controlling access to a limited resource. Low resource availability and a large overlap in fundamental niches make competition more likely. In these conditions we can expect two main outcomes as the result of contact between close competitors. First, one species may drive the other to localized extinction, as predicted by the competitive exclusion principle, which states that no two species can occupy the same niche indefinitely when resources are limited. Second, competition may lead to ecological character displacement [2,3], in which competition between similar individuals imposes disruptive selection on resource use and associated phenotypic characters, leading to divergence and reducing competition [4]. Character displacement allows close competitors to coexist by promoting divergence in resource use [5]. Phenotypic and life-history plasticity are generally important for successful animal invasions and freshwater fish commonly display high levels of plasticity $[6,7]$.

Chondrostoma $t$. toxostoma is a threatened, protected endemic cyprinid species from southern France. Part of its distribution range was colonized at the end of the XIX's century by the invasive Chondrostoma n. nasus, from Eastern Europe. The mitochondrial divergence between the two species calculated from cytochrome $b$ gene was about 7 My $[8,9]$. Where the two species are found in sympatry, a bi-directional hybridization phenomenon has been described in the Durance river (Rhone basin) [8]. The Durance river has been strongly structured by progressive urbanization and an increase in human activities along the river in the last 50 years. Various dams were constructed preventing fish from swimming upstream or downstream and leading to the formation of different water regulated environments. This situation promotes the coexistence of the two species in a "closed" environment (between dams) and makes both competition and hybridization phenomenon likely. Recently, Costedoat et al. [10] demonstrated the presence of the two parental species and different hybrid combinations in the Durance hybrid zone. Furthermore, they described a unidirectional change in the Chondrostoma's body shape, regardless of the genomic combination (i.e. pure or hybrid), when compared to allopatric populations. Considering that the two species and their hybrid presented this body shape deformation, the authors hypothesized that it could be a consequence of environmental adaptation rather than hybridization. However, the authors did not analyze either the species distribution, or the body shape deformation in regard to the environmental pressure degree that could be defined in the Durance river. Indeed, it is possible to define a highly regulated (HR) part (downstream) which has numerous dams and weirs leading to a confined environment, with irregular alternation of water flow, where the two species strongly overlap (through space and time) and a less regulated (LR) part in which the water flow is not severely regulated and in which fish can notably migrate to some tributaries, (further upstream). The habitat of the two species is known to be different in the literature [11], with moderate to fast-flowing, large to medium-sized rivers with a rock or gravel bottom for C. $n$. nasus (Cnn) and fast and clear water rivers with a cobble bottom for C. $t$. toxostoma $(\mathrm{Ctt})$. This situation raises two majors questions:

A century after the Cnn colonization in the Durance river what is the distribution of the two species and their hybrids in these two level of "anthropized" context (the LR and the HR zones)? Secondly, is there a difference in body shape between the specimen sampled in allopatry and those sampled in the two different anthropized parts of the river?

However, in the light of the differential environmental pressure in the Durance river (due to the fragmentation of the habitat), it appears obvious that others important parameters could interact with body shape. Indeed, morphology is also known to play a major role in determining the diet of a species, imposing physical constraints on the minimum and maximum size of prey that can be ingested, and affecting the efficiency of prey capture and consumption. A deep body shape is known to favor the consumption of benthic prey by increasing the manoeuvrability of the body, whereas a shallow body shape is likely to be beneficial for foraging on plankton $[12,13]$. Other important morphological characteristics define resource use: the mouth morphology, defined by the shape of the mouth [14-18] and the gape (maximal mouth dimensions) [1921]. The mouth of the Chondrotostoma species is furthermore a diagnosed character. Cnn is defined by a straight inferior mouth and a lower lip with a thick keratinized sheath [11], often linked to a specialized diet mainly based on benthic diatoms [22], whereas the inferior mouth of $\mathrm{Ctt}$, is arched (the lower jaw is often considered to be horseshoe-shaped -- first description Vallot [23]) and $C t t$ is known to feed on invertebrates and algae [11]. All these previous information underline the importance to obtain a good estimation of the "chondrostome diet behavior". However, dietary studies are difficult to carry out without direct observation of feeding behavior or without killing the animals. The fish of the Cyprinidae family have pharyngeal teeth, which crush everything ingested, making it difficult to recognize dietary components in the gut. For Chondrostoma species, we are also confronted with problems relating to species conservation 
status. The stable isotope analysis method presents advantages over conventional techniques in that it is compatible with non-lethal sampling and provides a short- or longterm integral picture (depending on the tissue used) of diet and metabolism [24-26].

Considering the Durance river context previously defined by differential anthropization levels, it seems relevant to test the modification and the interactions of the mouth morphology and diet behavior between the specimen sampled in allopatry and those sampled in the two different anthropized part of the river (the LR and the HR zones). To answer these questions, we performed a morphometric study on body and mouth shape (for which a new protocol was proposed) and used coefficient of condition and stable isotope analysis to determine the diet behavior considering the age and sex of each specimen. Modification of the different variable parameters and their interactions were tested for the Chondrostoma specimens present in the LR and the HR zones (representing the sympatric area) and those coming from the allopatric area.

\section{Results \\ Specimen identification and population description}

The mtDNA sequences of specimens sampled in allopatry confirmed their identification ( $\mathrm{Cnn}$ or $\mathrm{Ctt}$ ), with the exception of the Dniester population (figure 1). The cytochrome $b$ sequences obtained, confirmed that this population corresponded not to C. nasus nasus, but to its sister group (See Additional file 1: "Phylogenetic relationships between the Moldavian Dniester population samples and

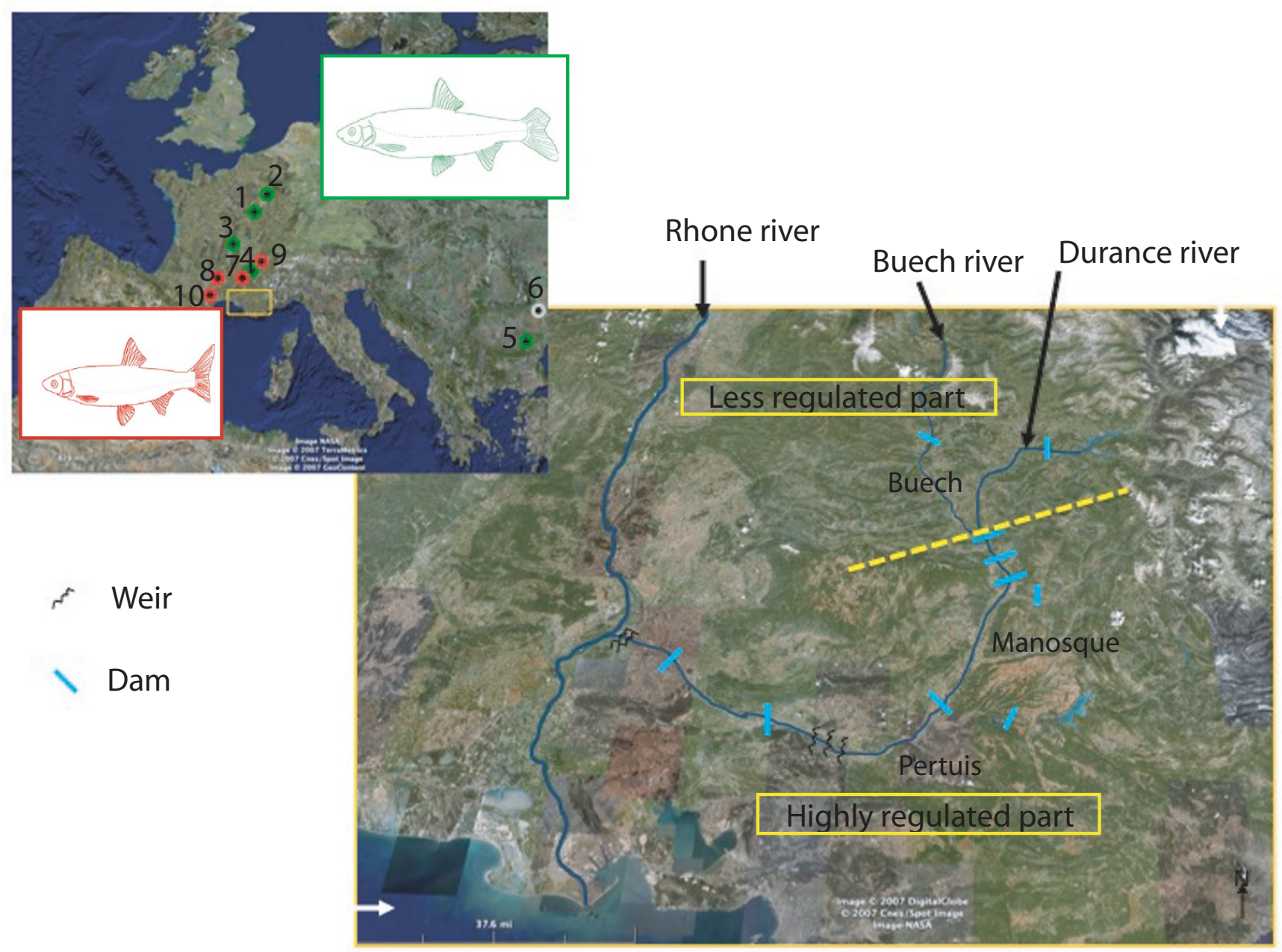

\section{Figure I}

Geographic distribution range. Green color represents allopatric $C$. nasus nasus populations I = Chee; 2 = Flet; $3=\mathrm{Allier}$; 4 = Usses; $5=$ Tisza; Grey color represents $C$. $n$. borysthenicum populations $6=$ Dniester (see text for more details). Red color represents allopatric $C$. toxostoma toxostoma populations $7=$ Ain; $8=$ Tarn; $9=$ Doubs; $10=$ Berre. Yellow square represents the hybrid zone (Durance river) with the split into Less Regulated part (Buech) and Highly Regulated part (Manosque-Pertuis). 
other C. nasus specimens"). We, therefore, used this population as an outgroup for the isotope and morphological analyses. The Genbank accession numbers of these Dniester population sequences are from GU112516 to GU112525.

Chi-squared tests did not show that the sex ratio is significantly different from 1 in the populations $\left(\chi^{2}=12.21\right.$, df $=7, \mathrm{P}>0.05$; except for Chee and Tisza were there is an excess of males; $\chi^{2}=22.54, \mathrm{df}=9, \mathrm{P}=0.0085$ ). Fish do not exhibit significantly different age distribution in the sympatric area $\left(\chi^{2}=32.19, \mathrm{df}=15, \mathrm{P}=0.080\right)$, with most individuals being between two and three years old. Three of the stations in allopatric conditions had older fish: Ain, Dniester and Tisza; and one had younger fish: Chee $\left(\chi^{2}=\right.$ 200.59, $\mathrm{df}=33, \mathrm{P}<10^{-6}$ ).

\section{Diversity index of the two species and their hybrids in the Durance}

The Shannon diversity index was significantly higher $(\mathrm{P}=$ $0.009)$ in the highly regulated (HR) part of the river $\left(\mathrm{H}_{\mathrm{Ma}}\right.$
$\mathrm{Pe}=3.35)$ than in the less regulated $(\mathrm{LR})$ part $\left(\mathrm{H}_{\mathrm{Bu}}=2.93\right)$, meaning that there are more different hybrid classes represented in Ma-Pe stations (55 hybrid classes) than in the Buech (44 hybrid classes), the two parental species ( $\mathrm{Cnn}$ and $\mathrm{Ctt}$ ) being present everywhere.

\section{Body shape deformation}

We carried out linear discriminant analysis on the populations considering all the allopatric and the hybrid zone populations. The first two axes were related to a species effect (Cnn vs $C t t$ ) and to treatment effect (allopatric vs sympatric). We observed the tendency towards a change in body shape in the sympatric population compared to allopatric population as described in a previous study [10]. Indeed, all hybrid zone specimens displayed a similar deformation of body shape, tending to blur the species effect (figure 2). Linear discriminant analysis of the treatment effect allowed us to characterize the body shape deformation. This deformation (with a tendency to a spindle-shaped body and the snout steered upward) depended on the sampling stations and was more accen-
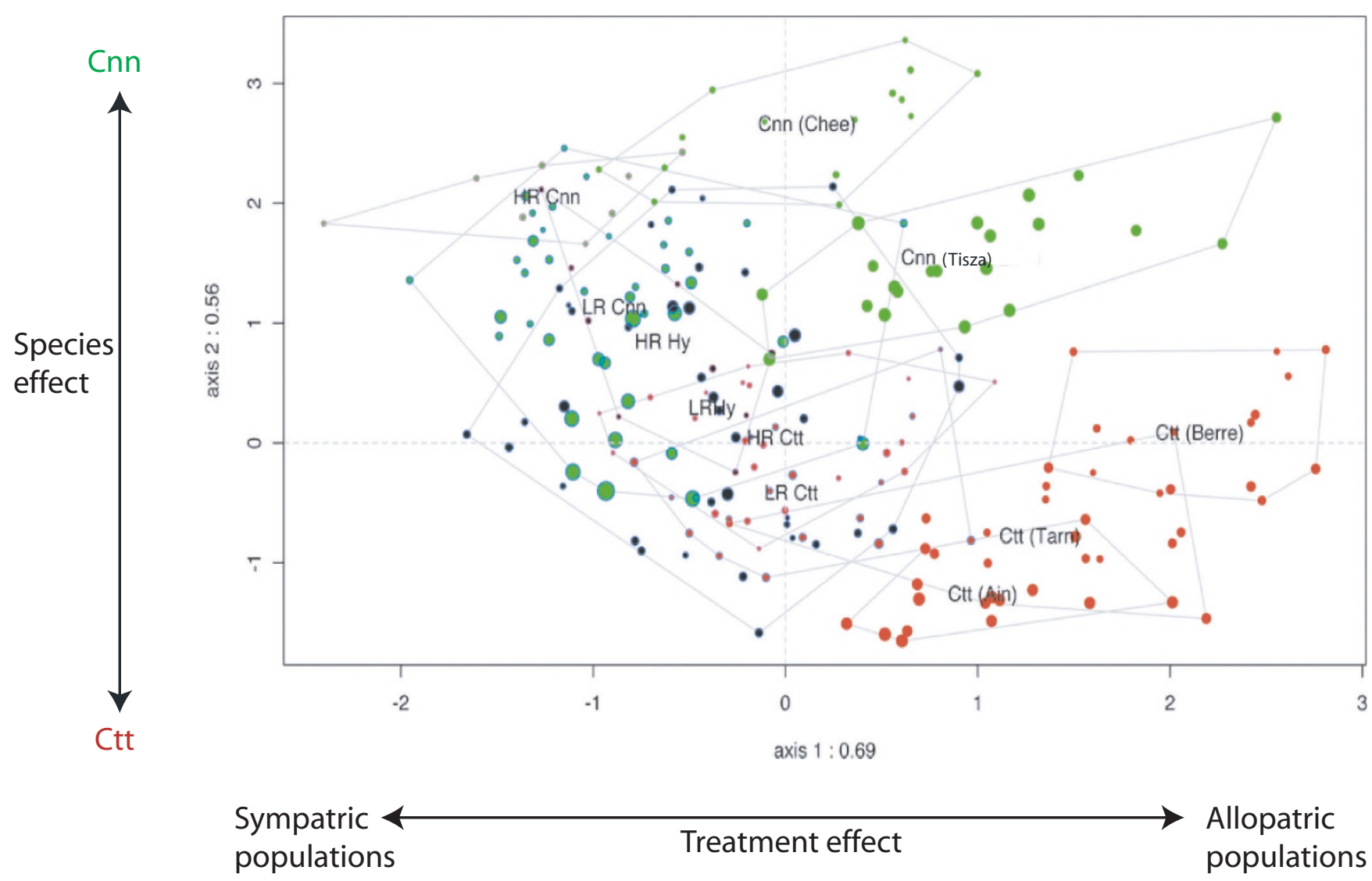

Figure 2

Discriminant analysis for plastic body morphological characters. Allopatric and sympatric populations including hybrids. Circle interior color: red = Ctt; green = Cnn; black: hybrids. Circle outline color: blue: LR part; pink: HR part. Circle diameter is proportional to the specimen size. 
tuated in the HR part than in the LR part, (mean value of -0.3306 for HR population and mean value of -0.1838 for LR ones; $\left.\mathrm{F}_{1,1106}=26.68 ; \mathrm{P}<10^{-6}\right)$, figure 3 .

\section{Mouth morphology}

\section{Mouth shape}

A superposition of the mouth shapes of all reference specimens is presented in figure 4 and represents the variation in mouth morphology observed in the two allopatric species. Despite an intra-species variance, we can discriminate the two species based on their mouth shape. Rather than a species effect in the hybrid zone we wanted to compare the treatment effect (i.e. allopatry vs sympatry) and determine if the body shape deformation in the hybrid zone was correlated to a mouth shape deformation. A difference in mouth morphology was observed between allopatric and sympatric specimens and corresponded to corner narrow shape $\left(\mathrm{F}_{1,909}=122.53, \mathrm{P}<10^{-6}\right.$, figure 5$)$. This deformation is not species dependent $\left(\mathrm{F}_{1,117}=1.45\right.$, $\mathrm{P}=0.23$, a detailed analysis of mouth shape deformation in function of hybrid combinations will be presented in Corse et al. in prep). This deformation of mouth morphology ( $R 2=11.88)$, was less linked to treatment effect than the modifications observed in body shape $(\mathrm{R} 2=53.39$ for the body shape) and has been visualized figure 5 . No significant differences were observed in the mouth morphology between specimens sampled in the HR part and those sampled in the LR part $\left(\mathrm{F}_{1,735}=0.44 ; \mathrm{P}=0.51\right)$.

\section{Mouth gape size}

The gape of the mouth (ratio gape size on body size) presented a significant effect according to the groups (the two species and their hybrids; $\mathrm{F}_{2,731}=45.68 ; \mathrm{P}<10^{-6}$ ) and was also significantly larger for specimens sampled in the LR part of the river than those sampled in the HR part $\left(F_{1,731}\right.$ = 4.53; $\mathrm{P}=0.034$ ), Additional file 2 .

\section{Diet behavior}

\section{Coefficient of condition: $K$}

In reference populations, with a correction for age effect, the mean $\mathrm{K}$ values for $\mathrm{Cnn}$ and $\mathrm{Ctt}$ were significantly different (respectively $\mathrm{K}=12.50$ and $\mathrm{K}=9.84 ; \mathrm{F}_{1,136}=49.92$ $\left.\mathrm{P}<10^{-6}\right)$. In the hybrid zone, the K values were not significantly different and a species effect was not observed $\left(\mathrm{K}_{\mathrm{Cnn}}=11.25 ; \mathrm{K}_{\mathrm{Ctt}}=11.27\right.$ and $\mathrm{K}_{\mathrm{Hy}}=11.21 ; \mathrm{F}_{2,1095}=0.77$; $\mathrm{P}=0.4645)$. Significant differences were observed between the LR zone and the HR zone (respectively, $\mathrm{K}_{\mathrm{LR}}=$ 10.97. and $\left.\mathrm{K}_{\mathrm{HR}}=11.41 ; \mathrm{F}_{1,1095}=28.73 \mathrm{P}<10^{-6}\right)$.

\section{Stable isotopes: $\mathrm{dC}^{13}$ and $\mathrm{dN}^{15}$}

The reproducibility was high for the different aliquots, with generally less than $0.09 \%$ variability for $\mathrm{d} 13 \mathrm{C}$ and $0.2 \%$ or $\mathrm{d} 15 \mathrm{~N}$.
We generated $\delta 13 \mathrm{C}-\delta 15 \mathrm{~N}$ bi-plots, with individuals plotted on the basis of their stable isotope signatures (figure $6)$. The allopatric populations of the two species covered a very large range, both on the $\mathrm{x}$-axis $(\delta 13 \mathrm{C}$ axis from $33.84 \%$ to $18.32 \%$ ) and on the $y$-axis ( $\delta 15$ I axis, from $6.47 \%$ o to $16.81 \%$ ). Surprisingly, we were unable to discriminate between the two species due to a large overlap between populations, but we observed a strong population effect (43 of the 45 pairwise comparisons corresponded to a significant mean difference). We were able to differentiate between all the populations if we considered the two-dimensional space defined by the $\delta 13 \mathrm{C}$ and $\delta 15 \mathrm{~N}$ axes (with the exception of the Doubs and Ain Ctt populations). This spreading over the isotope axes (greater on the $\delta 13 \mathrm{C}$ axis than on the $\delta 15 \mathrm{~N}$ axis) did not reflect common hydrogeographic catchment areas, and no grouping of populations based on geographic links was observed.

The sympatric populations covered a large part of the total range delimited by the species in allopatry (figure 6). The variance was greater in sympatry than in allopatry (Additional file 3). Furthermore, for Cnn and hybrids the variance in the LR zone was higher than the variance in the HR zone, whereas no difference was observed for the Ctt specimens. Based on the $\delta 15 \mathrm{~N}$, no significant difference was observed between the groups $\left(\delta 15 \mathrm{~N}_{C n n}=8.069\right.$; $\left.\delta 15 \mathrm{~N}_{C t t}=8.335 ; \delta 15 \mathrm{~N}_{\mathrm{Hy}}=8.19 ; \mathrm{F}_{2,125}=0.33, \mathrm{P}=0.7171\right)$ but the difference was significant between the populations of the two parts of the hybrid zone $\left(\delta 15 \mathrm{~N}_{\mathrm{HR}}=9.47\right.$; $\left.\delta 15 \mathrm{~N}_{\mathrm{LR}}=7.673 ; \mathrm{F}_{1,125}=22.36, \mathrm{P}<10^{-6}\right)$. No significant difference was observed on $\delta 13 \mathrm{C}$ for either of the groups $\left(\delta 13 \mathrm{C}_{C n n}=-27.39 ; \delta 13 \mathrm{C}_{\mathrm{Ctt}}=-27.53 ; \delta 13 \mathrm{C}_{\mathrm{Hy}}=-27.56\right.$; $\left.\mathrm{F}_{2,125}=0.33, \mathrm{P}=0.72\right)$, nor for the different parts of the hybrid zone $\left(\delta 13 \mathrm{C}_{\mathrm{HR}}=-27.69 ; \delta 13 \mathrm{C}_{\mathrm{LR}}=-27.42 ; \mathrm{F}_{1,125}=\right.$ $0.04, \mathrm{P}=0.84)$.

\section{Variable interactions}

We found a significant correlation $\left(r=-0.36\right.$; $\left.\mathrm{P}<10^{-6}\right)$ between the treatment effect on body shape and the treatment effect on the mouth shape of the specimens (Additional file 4). However, no correlation was found between the treatment effect on body shape and the stables isotopes (neither for the $\delta 15 \mathrm{C}$ nor for the $\delta 13 \mathrm{~N}$ ) no matter from where the specimens were sampled. No correlation was observed between the size of the gape and the stable isotope analysis, and no direct link could be made between diet behavior (visualized with the stable isotope analysis) and the relative "robustness" or degree of wellbeing (represented by K) of the fish (data not shown). 


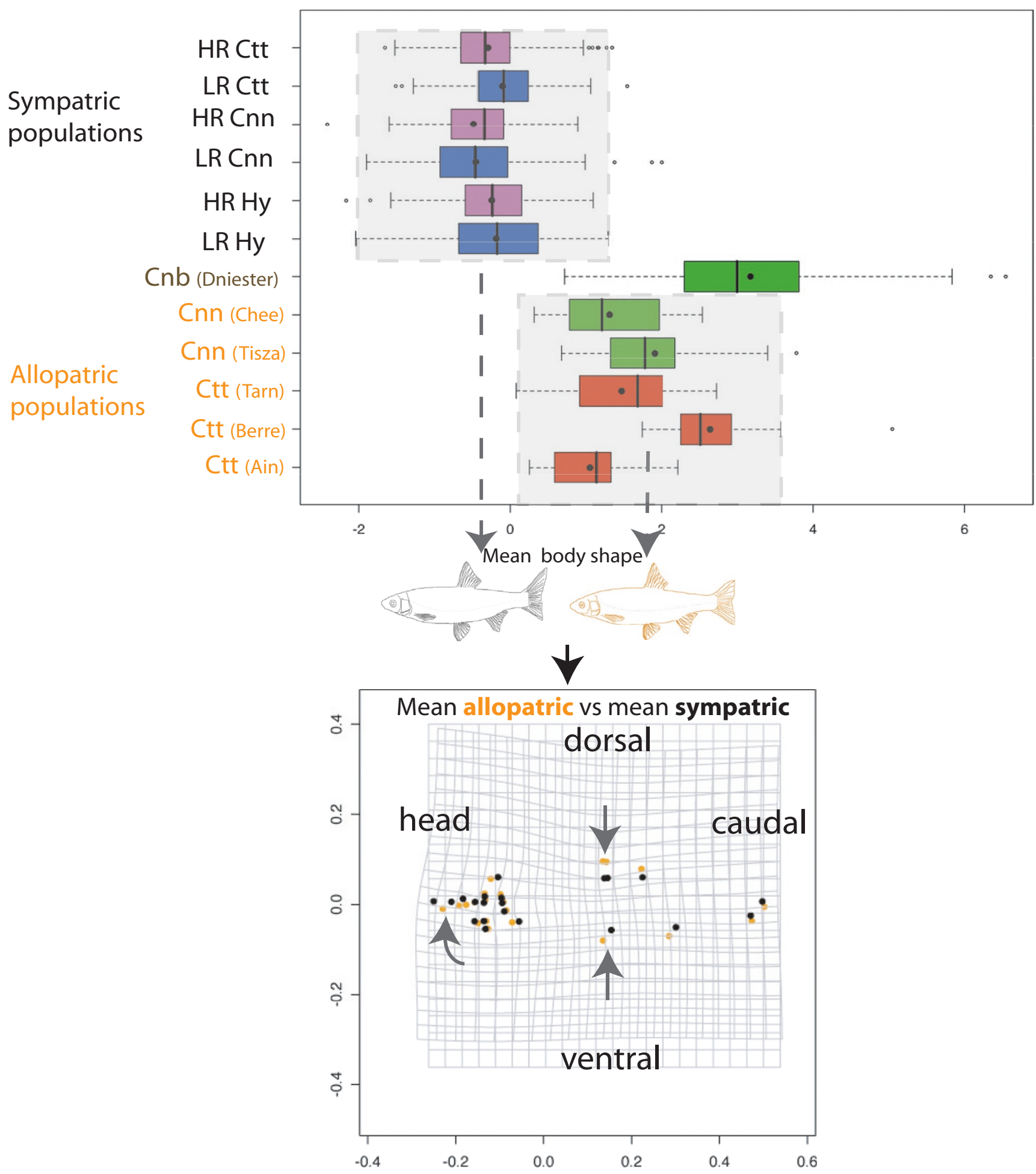

Figure 3

Box-plot of body shape in function of groups. Body shape is defined by axis of the linear discriminant analysis on treatment effect. Considered groups are: $\mathrm{Cnn}_{n}=$ Chondrostoma nasus nasus; $\mathrm{Ctt}=$ Chondrostoma toxostoma toxostoma; Hy = Hybrids; $\mathrm{HR}=$ Highly regulated river part; $L R=$ Less regulated river part. Deformation grid: orange: allopatric mean specimen; black sympatric mean specimen. The shape differences have been exaggerated three-fold for better visualization. Arrows indicate the main deformations (tendency to a spindle-shaped body and the snout steered upward in the hybrid zone). 


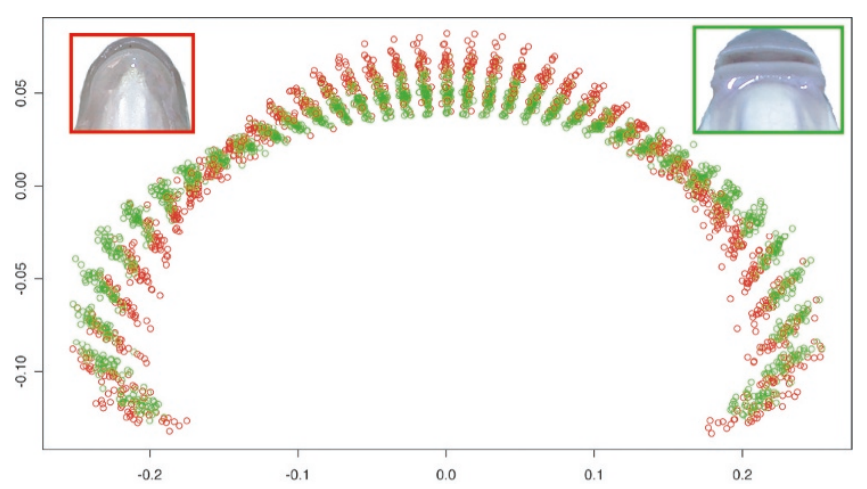

Figure 4

Mouth morphology analysis. The range of possible mouth shapes for the two species of Chondrostoma, corresponding to the superimposition of mouth landmarks after the procust superimposition of all allopatric specimens. Red circle = allopatric $\mathrm{Ctt}$; green circle $=$ allopatric $\mathrm{Cnn}$.

\section{Discussion \\ Competitive exclusion principle vs ecological character displacement}

The habitat of the two Chondrostomes is known to be sufficiently different [11] to expect the endemic Ctt to be predominantly in the LR part of the river (upstream) and the invasive Cnn into the HR part of the river (further downstream). However, we did not observe this distribution but the total opposite. Despite the presence of the two species throughout the river, $\mathrm{Ctt}$ was mainly present in the HR part (72\% of $\mathrm{Ctt} ; 4 \%$ of $\mathrm{Cnn}$ and $24 \%$ of hybrids) whereas in the LR part the two species were more equally represented (33\% of Ctt; $36 \%$ of $\mathrm{Cnn}$ and $31 \%$ of hybrids), calculated from [10]. The overwhelming majority of $\mathrm{Ctt}$ in the HR part could indicate the beginning of a competitive exclusion process in this more disturbed environment, with the curious advantage of the endemic species. The Shannon diversity index calculated in this study presents a stronger diversity in the HR part than in the LR part, indicating more different hybrid classes downstream than upstream (even if there is no significant difference between the two parts of the river in terms of rate of hybrids, calculated from [10]). These results illustrated that the different sympatric zone environments could have an influence on the distribution of the species and that environment pressure, associated with competition and apparition of new inter-species combinations (via hybridization), led species outside of their ecological preferendum (ecological transgressive segregation).

Furthermore, regardless of the species, we observed a body shape deformation between the two treatments (allopatric vs sympatric), with a tendency to a spindleshaped body with a snout steered upward in the hybrid zone. This deformation was environmentally dependent with a stronger accentuation in the HR part than in the LR part, but concerned both species and their hybrids. This over-all body shape convergence is not in accordance with the ecological character displacement theory wherein when two species overlap geographically the difference between them is accentuated in the zone of sympatry and weakened, or lost entirely, in the parts of their ranges outside this zone [2-4]. We can not assume that this result is due (or exclusively linked) to the hybridization process because the intensity and directionality of hybridization is not the same throughout the sympatric zone [10]. Adaptation for morphological specialization (here a spindle shaped body with a snout steered upward) have been explained in a wide range of fish species by a process of competition between co-existing populations which leads to resource partitioning [27]. However, we can also exclude the effect of species competition, because we did not observe a phenotypic divergence that could lead to reducing competition (e.g. benthic vs limnetic shape as found in sticklebacks [28]). But on the contrary all the specimens presented the same morphological tendency. Environmental pressure seemed to have more influence on the phenotype of the species complex than hybridization and competition. However, the slight difference in morphology observed between specimens sampled in the LR part of the river and those sampled in the HR part, tended to illustrate that the "regulated" effect of the river is not the main cause of this new morphology.

\section{Specialization in allopatric zones}

To improve interpretation of the sympatric results we detailed the diet behaviour of the two species based on the different allopatric populations. We did not observe a specific stable isotope signature and the direct link one species/one diet behaviour could not be assumed with our results. Some studies illustrated cases in which significant difference between the diets of two species was not observed based on muscle but was detected on liver (Cf. notably in [24]). However, even if we did not observe a species effect, we observed a population effect that led us to think that the used of muscle instead of other tissue is not the most parsimonious hypothesis to explain this pattern. If we assume that the baseline does not differ significantly between different tributaries or rivers, our results indicate different diets for each of the allopatric populations. If we assume a significant difference in the baseline between tributaries and rivers, we cannot compare trophic levels between populations. However, what is crucial in both cases, is that the dietary behaviour of the various allopatric populations is markedly similar for the specimen belonging to the same population and characterized by a narrow range (tendency to a specific diet behaviour) regardless of the considered species. In summary, the invasive and the endemic species displayed similar global plasticity when all populations were considered. The gen- 


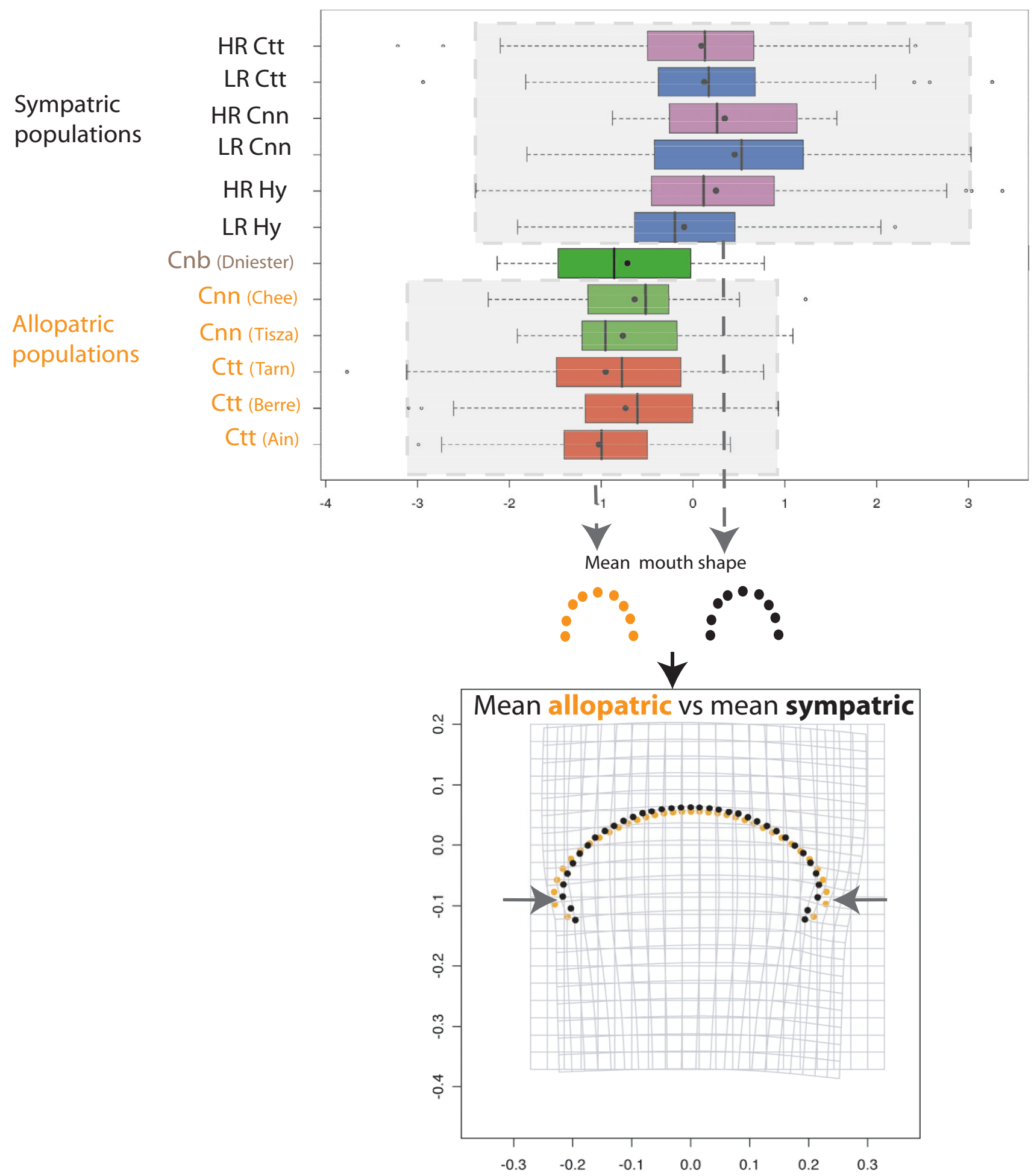

Figure 5

Box-plot of mouth shape in function of groups. Mouth shape is defined by the axis of the linear discriminant analysis on treatment effect. Considered groups are $\mathrm{Cnn}=$ Chondrostoma nasus nasus; $\mathrm{Ctt}=$ Chondrostoma toxostoma toxostoma; $\mathrm{Hy}=$ Hybrids; HR = Highly regulated river part; LR = Less regulated river part. Deformation grid: orange: allopatric mean mouth; black sympatric mean mouth. The shape differences have been exaggerated three-fold for better visualization. Arrows indicate the main deformations (corner narrow shape for hybrid zone specimens). 


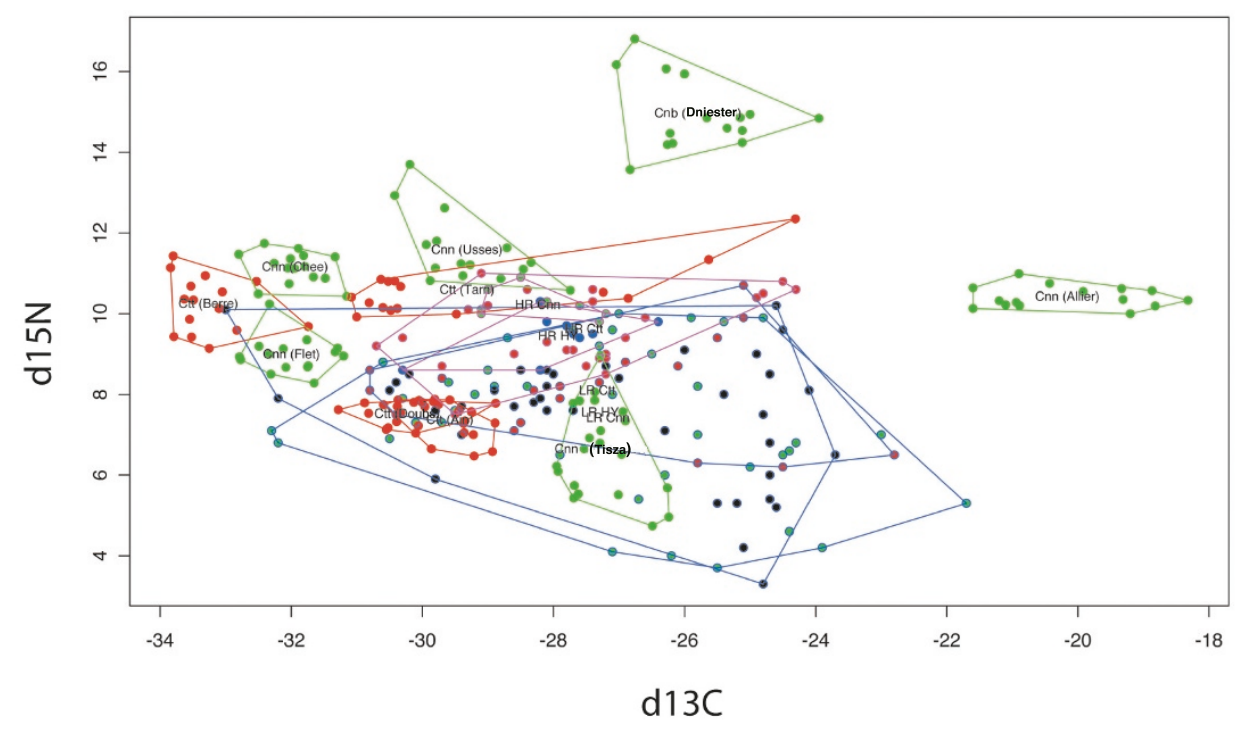

d15N

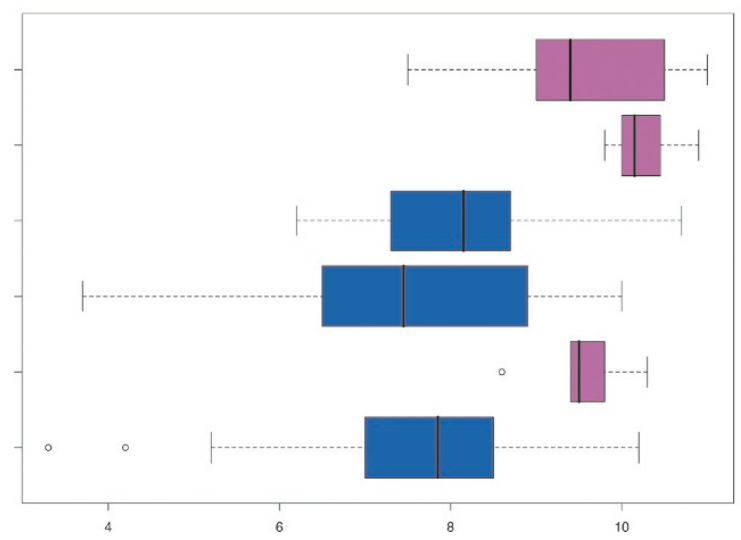

d13C

HR Ctt
HR Cnn
LR Ctt
LR Cnn
HR Hy
LR Hy

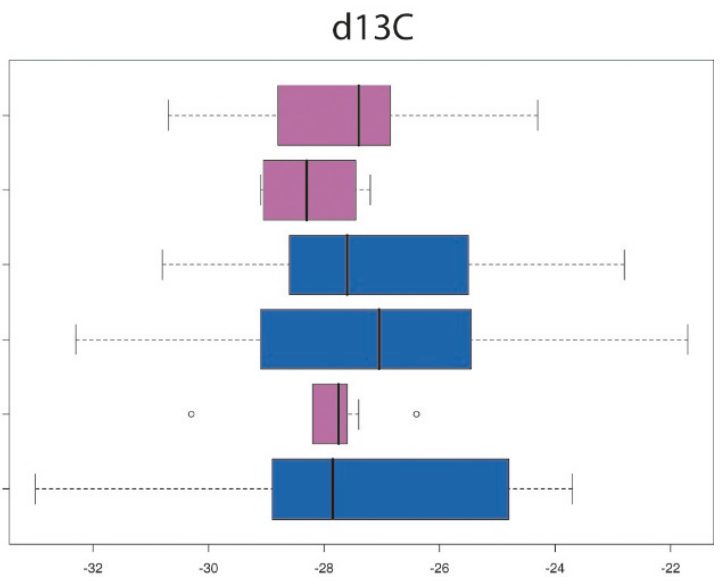

Figure 6

Stable isotope analyses. $\delta \mathrm{I} 3 \mathrm{C}-\delta \mathrm{I} 5 \mathrm{~N}$ bi-plots with individuals plotted based on their stable isotope signatures. Allopatric and sympatric populations. Circle interior color: red: Ctt; green: Cnn; black: hybrids; Circle outline color: blue: HR river part; pink: LR river part.

eral larger variances observed in the sympatric populations compared to allopatric populations could indicate that the specimens presented a more opportunistic dietary behaviour. These variances could be the result of hybridization, competition between species (sympatry), the water regulated effect, or a combination of these three factors.

\section{The trade-off in fish hybrid zone: morphological} convergence versus opportunistic diet behaviour

The tendency toward a more "limnetic" morph in the hybrid zone is, moreover, linked to a mouth shape deformation. Thus, we hypothesized that the phenotype deformation could depend on a significant alteration of food availability in the river and, therefore, on diet behaviour. The most obvious impact of introduced fish on native species is through competition for food [29]. Stable isotope analyses made it possible to determine both trophic levels (nitrogen ratio) and the spatial origin of food (carbon ratio) [30-34]. Furthermore, as we tested the age and sex difference for all the populations (none are significant), the difference observed in term of morphology, coefficient of condition, or stable isotope could not be due to these characteristics but to genetic and/or environmental effects. Comparisons of the dietary behaviour of the Chondrostoma "complex" in the sympatric zone did not lead to the identification of a species effect, but we observed a wide overlap of isotope signature between $\mathrm{Cnn}, \mathrm{Ctt}$ and 
hybrid specimens. This result was confirmed by the coefficient of condition that presented no significant species effect in the sympatric zone.

In summary, we observed a convergence in body and mouth shape in the sympatric zone, as well as a large variance in diet behaviour. However, no correlation was found between the sympatric effect on body shape and the stable isotopes (neither for the $\delta 15 \mathrm{C}$ nor for the $\delta 13 \mathrm{~N}$ ) regardless of where the specimens were sampled. Moreover, this morphological convergence could not be explained by the resource use diversity, also known as "individual specialization", in which it is assumed that a population is composed of ecologically heterogeneous individuals $[35,36]$. The absence of relation between morphology convergence and opportunistic diet behaviour appeared to be more complex than expected in the sympatric zone (whatever the anthropic level) and even if the species effect tended to be blurred in the sympatric zone some characters kept this species information (e.g. the mouth gape).

\section{To move towards the epigenetic base of adaptation}

Dietary shifts, from specialist to opportunist/generalist behaviour, are often seen as a sign of invasion aptitude $[37,38]$, favouring the colonization of new areas [39,40] and the results we obtained here did not confirm this tendency. This surprising result may be accounted for by plasticity in dietary behaviour that has been described globally for other cyprinid species [41]. Elshoud-Oldenhave and Osse [42] were the first to show that many teleosts adjust their alimentary strategy according to the environment in which they find themselves and the prey it contains (and not in function of their invasive aptitude). Liem [43] described this multiple potential strategy as "modulatory multiplicity". The use of this strategy makes teleost species highly versatile and could explained why we observed this populations difference regardless of the considered species even if at the population scales the diet behaviour appeared to be very specialised.

Furthermore, all the results obtained tend to show that water flow is not directly responsible for the specimen plasticity observed in the hybrid zone as was previously hypothesized [10]. However, we could not exclude an indirect effect of this parameter due to the influence of alternate patterns of clogs and leaches, which characterize this river. The Durance River is defined as an untamed Mediterranean river, notably under the influence of floods and drought periods. The major bed of the Durance is very large and the minor bed often oscillates over it. Thus, in this random change of water bed, the resilience periods vary in length and fish are dependent on the abundance of algal and invertebrate communities. We can therefore assume that the tendency toward an opportunistic dietary behaviour could be an adaptation to the rapid and stochastic changes in the river's benthic communities.

Finally, the results reported in this study deal with the theoretical concept based on the study of epigenetic mechanisms. These have been reported to have the potential to create either the so-called maintenance phenotype if the environmental conditions are unstable, poor or unpredictable (a typical situation for each invader, and in the case of this study also for $\mathrm{Ctt}$ that is likely to feel uncomfortable with the new competitor Cnn), or alternatively, the so called dispersal phenotype equipped to deal with conditions of dispersal in rich, unexploited "luxury environments". This concept has been further developed for fish, as the ontogenetic point was taken into account. As a result, a theory of alternative ontogenies has been proposed to explain the capacity of fish to create either specialized or generalized phenotypes and/or life-histories (e.g. in [44]). Finally, this theoretical concept has recently been applied to explain the success of some invasive fish and illustrate how biological invasion can also affect the invader itself, resulting in both genetic and epigenetic changes (e.g. in [45]). Epigenetic mechanisms (that can lead to alternative ontogenies) may have important implications for potential success in novel environment. The bighead goby study [45] and this Chondrostoma study tended to demonstrate the importance of considering such mechanisms in species adaptation and more globally in biological invasion studies and conservation biology.

\section{Materials and methods}

\section{Data collection, study area and individual identification}

We studied 1330 chondrostomes sampled in allopatry and sympatry. A subset of these samples came from [10], the rest represent new populations. The detail of population and sample size for each marker studied is presented in figure 1 and table 1 . All specimens used for isotope analysis were stored at $-80^{\circ} \mathrm{C}$ except those from Dniester and Berre, which were stored in $90 \%$ ethanol.

Whenever possible we determined the sex (defined after dissection or canulation method cf. [10]) and the age (defined by scalimetry) of the specimen. Morphology and diet behaviour could be influenced by these two factors, so we needed to check the sex ratio and the age range in each population before comparing them.

The identification of the chondrostomes of new allopatric populations was confirmed (i.e. to ensure that allopatric specimens were "pure") by DNA extraction, with amplification and sequencing of the mitochondrial cytochrome $b$ gene (details of the protocols in [46]). Hybrid zone specimens (Durance River) were identified in Costedoat et al. [10] by combining the alleles obtained for five molecular markers (mitochondrial cytochrome $b$ gene and four 
Table I: Sampled populations and sample size.

\begin{tabular}{|c|c|c|c|c|c|c|c|c|c|c|}
\hline Pop. & Treatment & N DNA & N Sex & N Age & N Body shape & N K & Study & N Mouth shape & N CN* & Study \\
\hline Ain $C_{t t}$ & Allopatry & 30 & 30 & 29 & 30 & 29 & This study & 22 & 15 & This study \\
\hline Berre Ctt & & 31 & 0 & 29 & 31 & 29 & This study & 28 & 15 & \\
\hline Chee Cnn & & 30 & 17 & 30 & 29 & 30 & This study & 30 & 15 & \\
\hline Tisza Cnn & & 24 & 19 & 24 & 24 & 23 & This study & 18 & 15 & \\
\hline Tarn Ctt & & 27 & 22 & 27 & 26 & 27 & This study & 21 & 15 & \\
\hline Dniester Cnb & & 29 & 0 & 12 & 26 & 12 & This study & 26 & 15 & \\
\hline LRHY & Sympatry & 136 & 110 & 133 & 134 & 126 & {$[10]$} & 107 & 42 & \\
\hline HRHY & & 169 & 79 & 169 & 166 & 169 & [10] & 115 & 10 & \\
\hline LRCnn & & 146 & 96 & $|4|$ & 145 & 135 & {$[10]$} & 109 & 40 & \\
\hline LRCtt & & 154 & 114 & 153 & 154 & 143 & {$[10]$} & 117 & 18 & \\
\hline HRCnn & & 34 & 14 & 33 & 34 & 33 & [10] & 22 & 8 & \\
\hline $\mathrm{HRCtt}$ & & 520 & 309 & 514 & 508 & 513 & {$[10]$} & 296 & 26 & \\
\hline Total & & 1330 & 810 & 1294 & 1307 & 1269 & & 911 & 234 & \\
\hline
\end{tabular}

$\mathrm{Cnn}=$ Chondrostoma nasus nasus; $\mathrm{Ctt}=$ Chondrostoma toxostoma toxostoma; $\mathrm{Hy}=$ Hybrids; $\mathrm{HR}=$ Highly regulated river part; $\mathrm{LR}=$ Less regulated river part. * For $\mathrm{CN}$ analysis we added one allopatric Ctt population (Doubs $\mathrm{N}=15$ ) and three $C n n$ populations (Allier $\mathrm{N}=15, \mathrm{Flet} \mathrm{N}=15, \mathrm{Usses} \mathrm{N}=15$ ). See text for details of the identification of $C$. $n$. borysthenicum in Dniester river.

nuclear introns). The authors identified the two parental species and 65 hybrid classes in the Durance. These 65 detailed hybrid classes were used in this study to calculate the Shannon diversity index to compare the diversity in the LR and HR parts of the sympatric zone. However, for statistical accuracy in the study of morphology and diet behaviour, we pooled all hybrids together because there were too few specimens in some of the 65 categories.

\section{Morphological analysis}

\section{Body shape}

Body shape was analyzed by the landmark-based geometric morphometric method. We defined 21 homologous landmarks on the body (cf. in [10]). All landmarks were digitized, using TpsDig software [47]. Landmark-based geometric morphometric methods were used to capture information about shape, by obtaining the $\mathrm{x}$ and $\mathrm{y}$ coordinates of homologous landmarks. Differences in the sets of coordinates between specimens due to scaling, rotation and translation were eliminated by a typical geometric morphometric approach $[48,49]$ in which the specimens were placed in a procruste superimposition on the iteratively estimated mean reference form, using the generalized procruste analysis (GPA) procedure. Points representing landmark configurations were then projected into Euclidean tangent space approximating the curved shape space.

\section{Mouth shape}

We investigated whether the difference in mouth morphology between the two Chondrostoma species (more precisely the lower lip shape) was correlated to dietary behaviour. This required a quantification of the difference in shape. All previous comparisons of mouth morphology in the Chondrostoma genus were subjective (simple description of the morph, see [50]). We characterized dif- ferences in mouth shape objectively (as was done for the body shape), using a morphometric approach based on the landmarks method. The main problem encountered with this approach is the definition of homologous points along the line of the mouth. In our case, the two lip corners are good candidates for homology between the mouths of the two species. We overcame the problem of homologous points by placing tracing paper with a semiradian drawn on it over the image of the mouth (we used Adobe Photoshop 5.0 for this superimposition). We then adjusted the diameter of the semi-radian to the width of the mouth, fitting the extremities of the radian to the two homologous points (lip corners). The semi-radian was divided by 37 lines (every $5^{\circ}$ ) and the intersection of each line with the edge of the lower lip was digitized with TpsDig version 1.40 [47]. This procedure was repeated for all the specimens studied, making comparisons of mouth shape possible.

\section{Diet behaviour analysis}

Stable isotope analysis (SIA) method

The two main elements used in stable isotope analysis for ecological research (and particularly for studies of the diet of fish [24,30,31,51-54] are carbon and nitrogen. Isotope ratios are reported in delta notation as per international standards: carbon from the Pee Dee limestone formation [55] and atmospheric nitrogen [56]. Nitrogen ratio is considered to characterize trophic level, whereas carbon ratio is considered to reflect the spatial origin of food [30$32,51,53,57,58]$.

In this study, we used 294 chondrostomes for carbon and nitrogen stable isotope analysis. These fish were chosen because of the possibility to use muscle tissue [58] and correspond to specimen sampled in 2001. The fish captured after 2001 were analyzed on the fields and then 
released, we did not used them for stable isotope analyses (but they were used for morphological study). Freezing is the ideal method for preserving specimens, but storage in ethanol does not seem to affect stable isotope ratios [59]. The two populations stored in ethanol (Dniester and Berre) were therefore included in this analysis. Muscle tissue was collected from the dorsal musculature posterior to the dorsal fin. Muscles were dehydrated by drying in an oven at $60^{\circ} \mathrm{C}$ for two days and were then crushed with individual sterile breakers. Samples must be dried sufficiently for grinding into a fine powder. Dried samples were sent to the Colorado Plateau Stable Isotope Laboratory of Northern (Arizona University) for the determination of $\% \mathrm{~N}, \% \mathrm{C}, \delta 15 \mathrm{~N}$, and $\delta 13 \mathrm{C}$ by isotope-ratio mass spectrometry.

First we analyzed the stable isotope data obtained for the allopatric populations, to estimate the isotope range (dietary behaviour) of each species. Then we integrated the results obtained for the sympatric zone, for which results were analyzed as a function of genotype (Ctt, Cnn or hybrid) and sampling station (highly regulated -HR- part or less regulated -LR- part).

\section{Coefficient of condition: $K$}

The relative robustness, or degree of well-being, can be expressed as the "coefficient of condition" [60]. The formula most often used is: $\mathrm{K}=\mathrm{W} / \mathrm{L} 3(\mathrm{~W}=$ the weight in grams; $\mathrm{L}=$ the standard length in decimeters).

\section{Statistical analyses}

Description of shape (body and mouth) variability was performed using linear discriminant analysis on group (Cnn, Ctt, Hy), "fragmentation"(HR river part and LR river part) and station variables. We compared the mean and variance for our variables of interest (isotopic signatures, shape deformation axes, mouth gape size, coefficient of condition) by way of analysis of variance. The corresponding factors were respectively defined by the species, the treatment and the fragmentation. If necessary, log transformations were performed to achieve homoscedasticity of the residuals. To take into account the incomplete design of the sampling scheme, effects were tested using a type III sum of squares. For each ANOVA, a global test was hence performed, followed, if necessary, by pairwise comparisons, (using Benjamini-Hochberg correction for multiple comparisons, [61]). Correlation between quantitative variables was analyzed using the BravaisPearson correlation coefficient. Shannon index was compared between groups by way of permutation test [62].

All statistical analyses were performed using R [63]. Deformation grids were visualized using the Tps grid function of the $\mathrm{R}$ shape package.

\section{Competing interests}

The authors declare that they have no competing interests.

\section{Authors' contributions}

EC and CC carried out the study and drafted the manuscript. AG Conceived the experiments. CC and AG designed the experiments and performed the manuscript preparation. EC, CC and NP analysed the data. EC, CC, JG and NP contributed to reagents/materials/analysis tools. $\mathrm{EC}, \mathrm{CC}, \mathrm{NP}, \mathrm{RC}$ and AG performed the field work. RC participated to the financial support.

\section{Additional material}

\begin{abstract}
Additional file 1
Phylogenetic relationships between the Moldavian Dniester population samples and other $\mathrm{C}$. nasus specimens. We carried out pairwise sequence comparisons, using the neighbor-joining method, based on Kimura-2-parameter distance model on cytochrome b data set. We tested the topology of the tree produced, by a non-parametric bootstrap method (only values higher than 50 are represented).

Click here for file

[http://www.biomedcentral.com/content/supplementary/17429994-6-26-S1.PDF]
\end{abstract}

\section{Additional file 2}

Box-plot of mouth gape in function of groups. Mouth gape is defined by the axis of the linear discriminant analysis on treatment effect. Considered groups are $\mathrm{Cnn}=$ Chondrostoma nasus nasus; $\mathrm{Cnb}$ : $\mathrm{C}$. $\mathrm{n}$. borysthenicum; $\mathrm{Ctt}=$ Chondrostoma toxostoma toxostoma; $\mathrm{Hy}=$ Hybrids; $H R=$ Highly regulated river part $L R=$ Less regulated river part. Click here for file

[http://www.biomedcentral.com/content/supplementary/17429994-6-26-S2.PDF]

\section{Additional file 3}

d13C and d15N variance by groups. Cnn = Chondrostoma nasus nasus; $\mathrm{Ctt}=$ Chondrostoma toxostoma toxostoma; $H y=H y b r i d s ;$ $H R=$ Highly regulated river part $L R=$ Less regulated river part. Click here for file

[http://www.biomedcentral.com/content/supplementary/17429994-6-26-S3.PDF]

\section{Additional file 4}

Correlation between body shape and mouth shape's treatment effect. Circle interior color: $r e d=\mathrm{Ctt} ;$ green $=\mathrm{Cnn}$; black: hybrids. Circle outline color: blue: LR part; pink: HR part. Circle diameter is proportional to the specimen size.

Click here for file

[http://www.biomedcentral.com/content/supplementary/17429994-6-26-S4.PDF]

\section{Acknowledgements}

We thank Jean François Martin for complementary stable isotope results and Ginny Hekinian for her kind assistance. We thank two anonymous reviewers for their helpful comments. 
This work was supported partly (PhD grant) by the region PACA and SMAVD

\section{References}

I. Bohn T, Amundsen PA: The competitive edge of an invading specialist. Ecology 200I, 82:2I50-2I63.

2. Losos JB: Ecological character displacement and the study of adaptation. P Natl Acad Sci USA 2000, 97( I I ):5693-5695.

3. Schluter D: Ecology and the origin of species. Trends Ecol Evol 200I, I 6(7):372-380.

4. Dayan T, Simberloff D: Ecological and community-wide character displacement: the next generation. Ecol Lett 2005, 8:875-894.

5. Pfennig DW, Rice AM, Martin RA: Ecological opportunity and phenotypic plasticity interact to promote character displacement and species coexistence. Ecol Soc Am 2006, 87:769-779.

6. Ehrlich P: Attributes of invaders and the invading processes: vertebrates. In Biological Invasions: a Global Perspective Edited by: Drake JA, Mooney HA, di Castri F, Groves RH, Kruger FJ, Rejmanek M, Williamson M. J.Wiley publisher, Chichester, U.K; 1989:315-328.

7. Williamson M: Biological Invasions Edited by T.J Press, Chapman \& Hall Publisher, London, U.K; 1996.

8. Costedoat C, Pech N, Salducci D, Chappaz R, Gilles A: Evolution of mosaic hybrid zone between invasive and endemic species of Cyprinidae through space and time. Biol J Linn Soc 2005, 85:135-155.

9. Doadrio I, Carmona JA: Phylogenetic relationships and biogeography of the genus Chondrostoma inferred from mitochondrial DNA sequences. Mol Phyl Evol 2004, 33:802-8I5.

10. Costedoat C, Pech N, Chappaz R, Gilles A: Novelties in Hybrid Zones: Crossroads between Population Genomic and Ecological Approaches. PLoS ONE 2007, 2(4):e357.

I I. Kottelat M, Freyhof J: Handbook of European Freshwater Fishes Edited by Publication Kottelat; 2007:646.

12. Webb PW: Body and fin form and strike tactics of 4 teleosts predators attacking fathead minnow (PimephalesPromelas) prey. Can J Fish Aquat Sci 1984, 4 I: I 57- I65.

13. Domenici P: Habitat, body design and the swimming performance of fish. In Vertebrate biomechanics and evolution Edited by: Bels VL, Gasc JP, Casinos A. BIOS Scientific Publishers Ltd, Oxford, U. K; 2003:137-160.

14. Wimberger PH: Plasticity of fish body shape- The effects of diet, development, family and age in $\mathbf{2}$ species of Geophagus (pisces, Cichlida). Biol J Linn Soc 1992, 45:197-218.

15. Wainwright PC, Richard BA: Predicting patterns of prey use from morphology of fishes. Env Biol Fish 1995, 44:97-I I3.

16. Adams CE, Huntingford FA: The functional significance of inherited differences in feeding morphology in a sympatric polymorphic population of Arctic charr. Evol Ecol 2002, 16:15-25.

17. Kassam DD, Sato S, Yamaoka K: Landmark-based morphometric analysis of the body shape of two sympatric species, Ctenopharynx pictus and Otopharynx sp. "heterodon nankhumba" (Teleostei: Cichlidae), from Lake Malawi. Ichthyol Res 2002, 49:340-345.

18. Langerhans RB, Layman CA, Langerhans CA, Dewitt T: Habitatassociated morphological divergens in two Neotropical fish species. Biol J Linn Soc 2003, 80:689-698.

19. Piet GJ: Ecomorphology of a size-structured tropical freshwater fish community. Env Biol Fish 1998, 5 I:67-86.

20. Kruitwagen G, Nagelkerken I, Lugendo BR, Pratap HB, WendelaarBonga SE: Influence of morphology and amphibious life-style on the feeding ecology of the mudskipper Periophthalmus argentilineatus. J Fish Biol 2007:39-52.

21. Huckins CJF: Functional linkages among morphology, feeding performance, diet, and competitive ability in molluscivorous sunfish. Ecology 1997, 78:240I-24I4.

22. Freyhof J: Feeding traces as an indicator of habitat choice in nase, Chondrostoma nasus. Folia Zool 1995, 44:57-6I.

23. Vallot JN: Ichthyologie Française ou Histoire naturelle des poissons d'eau douce de la France ed. Frantin 1837.

24. Grey J: The use of stable isotope analyses in freshwater ecology: current awareness. Pol J Ecol 2006, 54:563-584.

25. Guelinckx J, Maes J, Driessche P Van Den, Geysen B, Dehairs F: Changes in delta C-I3 and delta N-I5 in different tissues of juvenile sand goby Pomatoschistus minutus: a laboratory diet-switch experiment. Mar Ecol-Prog Ser 2007, 34 I:205-2I5.

26. Jochen BW, Harrod C, Brunner S, Salazar S, Trillmich F, Tautz D: Tracing early stages of species differentiation: Ecological, morphological and genetic divergence of Galápagos sea lion populations. BMC Evol Ecol 2008, 8: I 50.

27. Robinson BW, Wilson DW: Character release and displacement in fishes: a neglected literature. Am Nat 1994, | 44:596-627.

28. Cresko WA, Baker JA: Two morphotypes of lacustrine threespine stickleback, Gasterosteus aculeatus, in Benka Lake, Alaska. Environ Biol Fish 1996, 45:343-350.

29. Moyle $\mathrm{PB}$, Light $\mathrm{T}$ : Biological invasions of fresh water: empirical rules and assembly theory. Biol Conserv 1996, 78:149-162.

30. Dufour E, Gerdeaux D: Apports des isotopes stables $\mathrm{CI} 3 / \mathrm{CI}$, NI5/NI4, OI8/OI6, S36/S34, SR87/SR86 aux études écologiques sur les poissons. Cybium 2001, 25:369-382.

31. DeNiro MJ, Epstein S: Hydrogen isotope ratios of mouse tissues are influenced by a variety of factors other than diet. Science | 981, 2 | 4: |374-। 376.

32. Minagawa M, E Wada E: Stepwise enrichment of I5-N along food chains: further evidence and the relation between I5-N and animal age. Geochim Cosmochim Acta 1984, 48: I I35-1 I 40.

33. Finlay JC, Power ME, Cabana G: Effects of Water Velocity on Algal Carbon Isotope Ratios: Implications for River Food Web Studies. Limnol Oceanogr 1999, 44(5): I I98-I 203.

34. Trudeau V, Rasmussen JB: The Effect of Water Velocity on Stable Carbon and Nitrogen Isotope Signatures of Periphyton. Limnol Oceanogr 2003, 48(6):2194-2199.

35. Bolnick DI, Svanback R, Fordyce JA, Yang LH, Davis JM, Hulsey GD, Forrister ML: The ecology of individuals: incidence and implications of individual specialization. Am Nat I6 I: |-28.

36. Svanback R, Bolnick DI: Intraspecific competition drives increased resource use diversity within a natural population. Proc R Soc B 274:839-844.

37. Agrawal AA: Phenotypic plasticity in the interactions and evolution of species. Science 200I, 294:321-326.

38. Gherardi F: Crayfish invading Europe: the case study of Procambarus clarkii. Mar Freshw Behav Phys 2006, 39(3): I75-191.

39. Bergmann G, Motta P: Diet and morphology through ontogeny of the nonindigenous Mayan cichlid 'Cichlasoma (Nandopsis)' urophthalmus (Günther I 862) in southern Florida. Environ Biol Fishes 2005, 72(2):205-2I I.

40. Ribeiro F, Orjuela RL, Magalhães MF, Collares-Pereira MJ: Variability in feeding ecology of a South American cichlid: a reason for successful invasion in mediterranean-type rivers? Ecol Freshw Fish 2007, I 6(4):559-569.

4I. Garcia-Berthou E, Moreno-Amich R, Coden A: Introduction of exotic fish into a Mediterranean lake over a $\mathbf{9 0}$-year period. Arch Hydrob 2000, I 49(2):27I-284.

42. Elshoud-Oldenhave MJW, Osse JWM: Functional morphology of the feeding system in the ruff Gymnocephalus cernua (L. I 758) - (Teleostei, Percidae). J Morphol 1976, I 50:399-422.

43. Liem KE: Modulatory multiplicity in the functional repertoire of the feeding mechanism in cichlid fishes. I Piscivores J Morph 1979, 158:323-360.

44. Balon EK: The Epigenetic Mechanisms of Bifurcation and Alternative Life-history Styles. In Alternative Life-History Styles of Animals Edited by: Bruton MN. Dordrecht: Kluwer Academic Publishers; 1989:467-50I.

45. Kovac V, Copp GH, Sousa RP: Life-history traits of invasive bighead goby Neogobius kessleri (Gunther, I 86I) from the middle Danube River, with a reflection on which goby species may win the competition. J Appl lchthyol 2009, 25:33-37.

46. Costedoat C, Pech N, Chappaz R, Salducci MD, Lim P, Gilles A: Study of introgressive hybridization between Chondrostoma t. toxostoma and Chondrostoma n. nasus (Teleostei, Cyprinidae) using multiple approaches. Cybium 2004, 28:5 I-6I.

47. Rohlf FJ: tpsDig, version I.40. Department of Ecology and Evolution State University of New York at StonyBrook; 2004.

48. Dryden I, Mardia K: Statistical shape analysis New-York: John Wiley\&Sons, USA; 1998:347.

49. Rohlf FJ: Shape statistics: procustes superimpositions and tangent spaces. J Class 1999, I 6:197-223. 
50. Mathias P: Etude du genre Chondrostoma dans l'Europe occidentale et la région circumméditerranéenne. Mémoires de la société zoologique 1921:52.

51. DeNiro MJ, Epstein S: Infuence of diet on the distribution of carbon isotopes in animals. Geochim Cosmochim Acta 1978, 42:495-506.

52. Hesslein RH, Hallard KA, Ramlal P: Replacement of sulfur, carbon, and nitrogen in tissue of growing broad whitefish (Coregonus-nasus) in response to a change in diet traced by delta S34, Delta CI3 and delta NI5. Can J Fish Aquat Sci 1993, 50:207I-2076

53. Jardine TD, McGeachy SA, Paton CM, Savoie M, Cunjak RA: Stable isotopes in aquatic systems: Sample preparation, analysis, and interpretation. Can Manuscr Rep Fish Aquat Sci 2003, 2656:39.

54. Cucherousset J, Aymes JC, Santoul F, Céréghino R: Stable isotope evidence of trophic interactions between introduced brook trout (Salvelinus fontinalis) and native brown trout (Salmo trutta) in a mountain stream of southwest France. J Fish Biol 2007, 71:210-223.

55. Craig $\mathrm{H}$ : Isotopic standards for carbon and oxygen and correction factors for mass-spectrometric analysis of carbon dioxide. Geochim Cosmochim Acta 1957, I 2:133-149.

56. Mariotti A: Atmospheric nitrogen is a reliable standard for natural I5N abundance measurements. Nature 1983, 303:685-687.

57. Zanden MJ Vander, Hulshof M, Ridgway MS, Rasmussen JB: Application of stable isotope techniques to trophic studies of age-0 smallmouth bass. T Am Fish Soc 1998, 1 27:729-739.

58. Jardine TD, Gray MA, McWilliam SM, Cunjak RA: Stable isotope variability in tissues of temperate stream fishes. $T$ Am Fish Soc 2005, I34: I 103-11110.

59. Hobson KA, Gibbs HL, Gloutney ML: Preservation of blood and tissue samples for stable-carbon and stable- nitrogen isotope analysis. Can J Zool I997, 75:I720-I723.

60. Gray MA, Curry AR, Munkittrick KR: Non lethal sampling methods for assessing environmental impacts using small bodied sentinel fish species. Water Qual Res J Canada 2002, 37:|95-2 I I.

61. Benjamni $Y$, Hochberg $Y$ : Controlling the false discovery rate: a practical and powerful approach to multiple testing. J R Stat Soc B 1995, 57:289-300.

62. Eddington ES: Randomization Tests New York: Dekker; 1995:409.

63. R Development Core Team: $\mathbf{R}$, a language and environment for statistical computing. 1995 [http://www.R-project.org]. R Foundation for Statistical Computing. Vienna, Austria ISBN 3-90005 I-07-0

Publish with Bio Med Central and every scientist can read your work free of charge

"BioMed Central will be the most significant development for disseminating the results of biomedical research in our lifetime. "

Sir Paul Nurse, Cancer Research UK

Your research papers will be:

- available free of charge to the entire biomedical community

- peer reviewed and published immediately upon acceptance

- cited in PubMed and archived on PubMed Central

- yours - you keep the copyright
BioMedcentral 